\title{
Times have changed - Is it time to consider restructuring the CAG?
}

\author{
William G Paterson MD FRCPC \\ President, Canadian Association of Gastroenterology \\ Department of Medicine, Queen's University, Kingston, Ontario
}

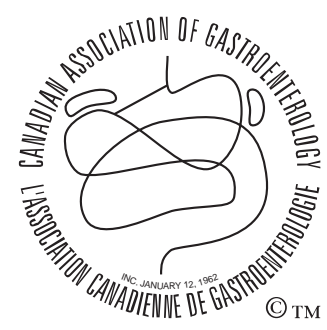

En français voir page 55

F ollowing the 2005 annual general meeting of the Canadian Association of Gastroenterology (CAG) where certain proposals for CAG bylaw revisions were tabled, the CAG Board decided to create an ad hoc committee to take a more comprehensive look at restructuring the CAG management, which in turn would result in proposals for bylaw amendments. A committee consisting of William Paterson, Des Leddin, Ronald Bridges, Mary Perdue, John Wallace and Paul Sinclair was formed. This committee endorsed the need to make fundamental changes in the structure of the CAG management to streamline the operations of the organization and better achieve its strategic goals. It was further agreed that the process for implementing change must involve broad consultation with the CAG Board and the membership. The present document represents the first step in this consultative process.

\section{RATIONALE FOR CHANGE}

The CAG's long-term strategic plan, published in 2004, included a significant move toward public relations and advocacy. However, the current structure of the organization is largely derived from its previous mandate, which was focused on research and education. A consensus has emerged among the CAG Executive that the organization is not optimally configured to pursue the new strategic plan.

The human resources available to run the organization are limited. The relative shortage of gastroenterologists in Canada has been well documented by the association. As a result, most gastroenterologists are already overly committed to other responsibilities. It is therefore important that we be as efficient as possible in using the human resources we have to conduct the volunteer work of the organization. In some instances, committees may no longer have the mandate for which they were originally developed, and certain new needs of the organization are not being met by the current committee structure.

With the new advocacy role, the work of the CAG Executive has expanded significantly. There is concern that many excellent individuals would not be able or willing to take on a leadership position (President Elect, President and Past President) within the association that entails a significant six-year commitment.
Given the expansion of committees, the current CAG board structure has become rather unwieldy. In fact, the current CAG Board consisting of 22 members is considerably beyond the maximum of 15 recommended by governance experts (1).

\section{PROPOSED CHANGES IN THE CAG'S ORGANIZATIONAL STRUCTURE (FIGURE 1)}

1. The terms of office for the members of the CAG Executive (the leadership stream), consisting of an executive Vice-President, President Elect, President and Past President, will be decreased from six to four years. Each position will be held consecutively for a one-year period. Revised job descriptions for these positions will be required.

2. The positions of VP Finance and Treasurer will be combined.

3. The VP Secretary position will be converted to VP Administrative Affairs, which will include responsibility for all Administration and Communication committees (see below).

4. Committee restructuring

- In recent years, this has been modified so that there is a VP of Clinical Affairs and VP of Education, each of whom oversee a number of committees within the clinical and education portfolios, respectively. This structure has worked extremely well to date. It is proposed that we will expand this to include VP Administration who will oversee the Admissions, Archives, Communications, Ethics, Finance, Gender and Nominations committees. In addition, the current Chair of the Research Committee will become VP Research.

- A new Public Relations and Advocacy committee will be formed, which will be under the jurisdiction of the VP Administrative Affairs. This committee, which will be chaired by the CAG Past President, will:

The CAG is proud to acknowledge its Benefactor Corporate Sponsors:

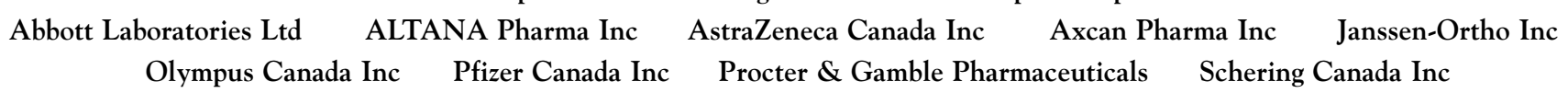




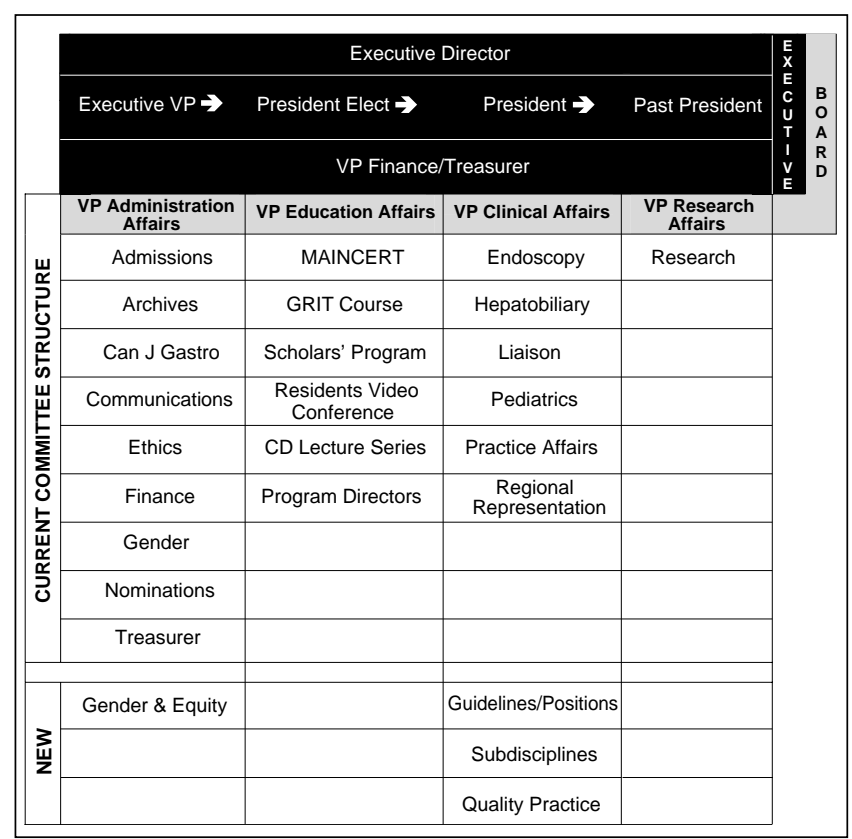

Figure 1) Proposed changes in the Canadian Association of Gastroenterology's organizational structure. CD Compact disc; Can J Gastro The Canadian Journal of Gastroenterology; GRIT Gastroenterology residents in training; MAINCERT Maintenance of certification

- Provide advice regarding advocacy in public relation issues to the Executive and to the Canadian Digestive Health Foundation;

- Liaise with regional representatives to facilitate advocacy at the provincial government and local hospital level;

- Strategically plan future public relations and advocacy programs for the CAG; and

- Provide human resources for rapid response to media requests for interviews on issues of interest to Canadian gastroenterology.

- Current committees have been asked to review their mandates and come forward with recommendations that may include eliminating or amalgamating current committees, establishing new committees or changing the mandate of existing committees. Examples of suggestions that have already been put forward for discussion include:

- Expanding the mandate of the Gender committee to Gender and Equity, so as to address issues such as under-representation of aboriginals in gastroenterology;

- Establishing a Guidelines/Positions Statement committee within the Clinical Affairs portfolio;

- Expanding the role of the Liaison committee to include international relations;

- Abolishing the Hepatobiliary committee, which is currently an outlier as the only organ-specific committee within the CAG. In its place, we could consider having a single 'Subdisciplines' committee with representatives from, for example, liver, pancreato-biliary, inflammatory bowel disease, esophagogastroduodenoscopy, motility/functional disease and cancer. Alternatively, we could consider having permanent positions on the Canadian Digestive Diseases Week implementation committee for representatives from these subdisciplines; and

- Establishing a 'Quality Practice' committee within the Clinical Affairs portfolio.

As stated earlier, this is the initial consultative step with the CAG membership. We have tried to formulate a new, more effective model for the association and have provided some initial thoughts surrounding change as a focus for discussion. However, these changes are by no means 'cast in stone' and should be reviewed and considered carefully.

Your suggestions and comments are welcome! Please send them to:

The CAG National Office

2902 South Sheridan Way, Suite 201,

Oakville, Ontario L6J 7L6.

Fax 905-829-0242 or e-mail cagoffice@cag-acg.org

\section{REFERENCES}

1. Oliver C, Conduff M, Edsall S. The Policy Governance Fieldbook: Practical Lessons, Tips, and Tools from the Experiences of Real-World Boards. John Wiley \& Sons Canada Ltd, 1999. 


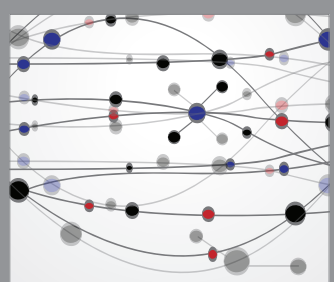

The Scientific World Journal
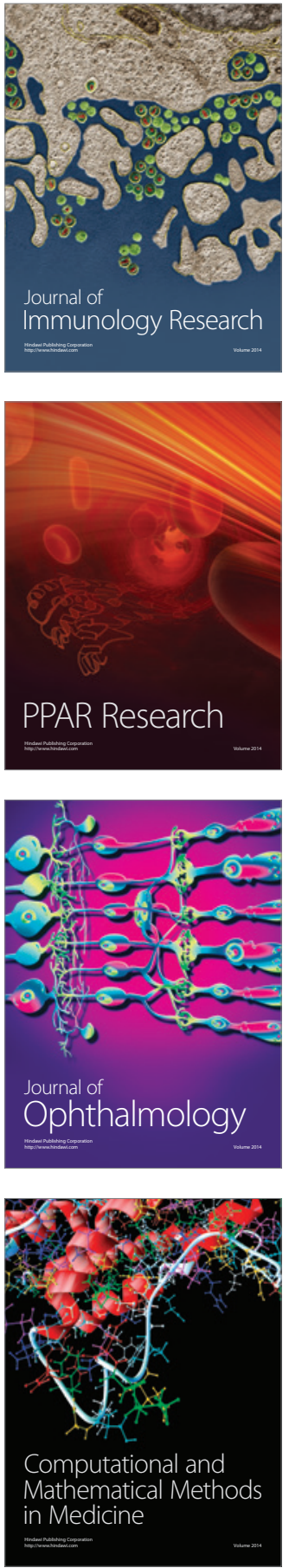

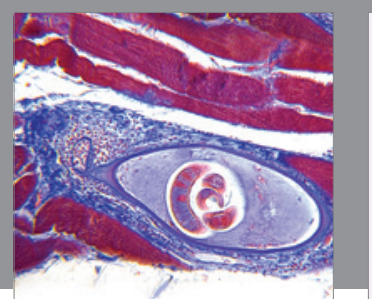

Gastroenterology Research and Practice

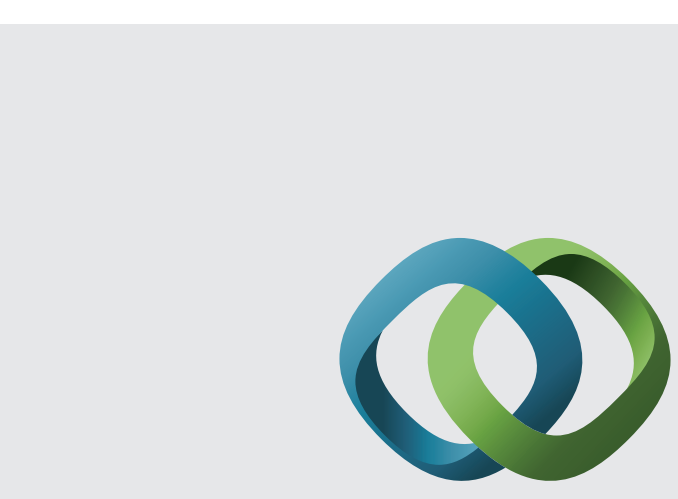

\section{Hindawi}

Submit your manuscripts at

http://www.hindawi.com
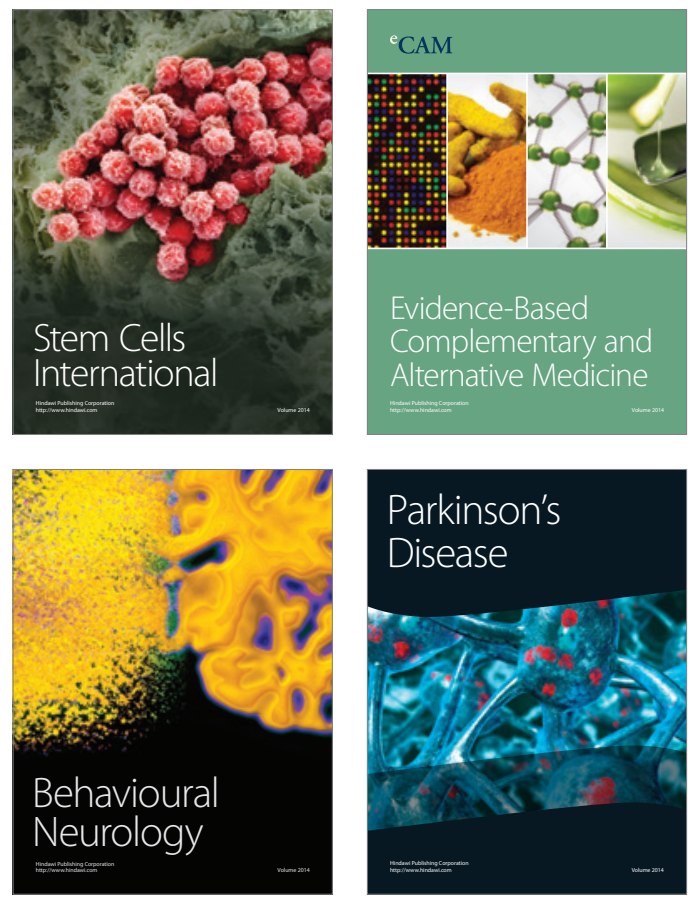
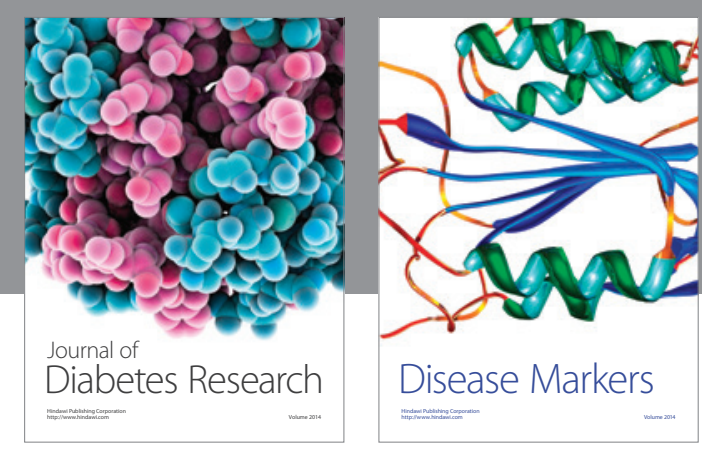

Disease Markers
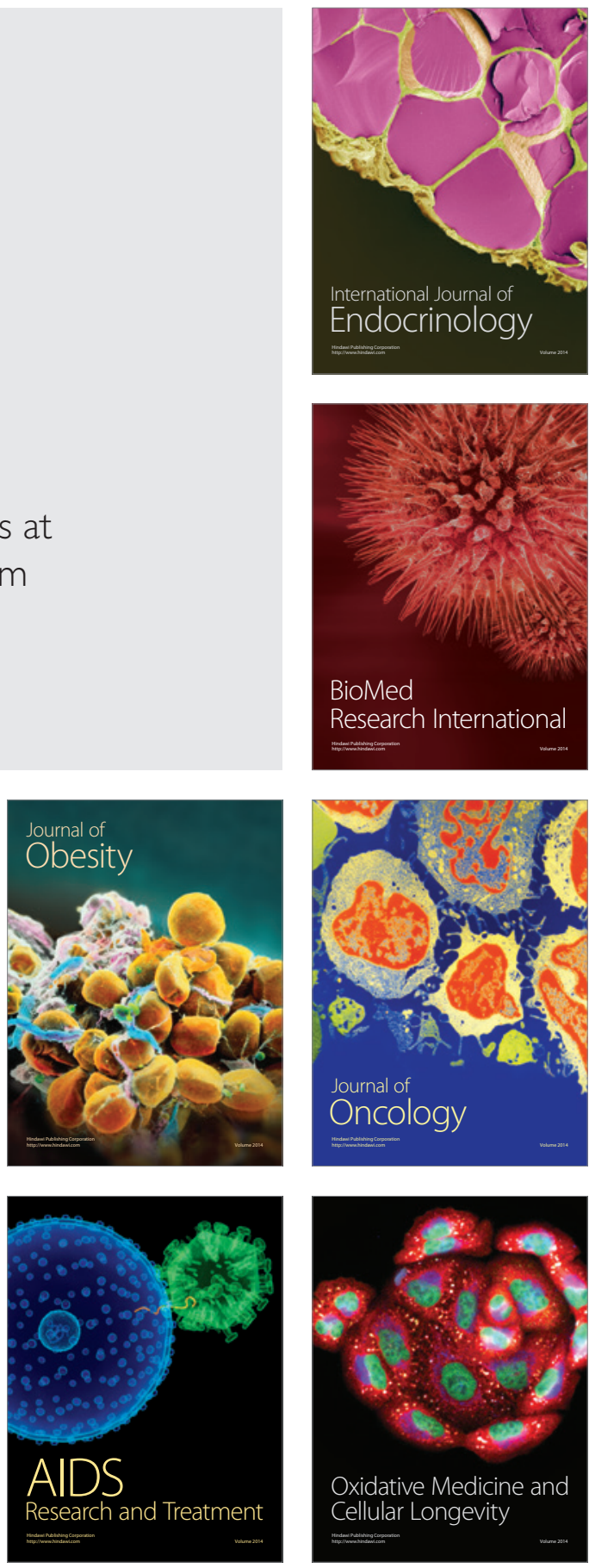